Virginia Commonwealth University VCU Scholars Compass

2004

\title{
Interactions of Au cluster anions with oxygen
}

Qiang Sun

Virginia Commonwealth University

Puru Jena

Virginia Commonwealth University

Young Dok Kim

University of Konstanz

Matthias Fischer

University of Konstanz

Gerd Ganteför

University of Konstanz

Follow this and additional works at: http://scholarscompass.vcu.edu/phys_pubs

Part of the Physics Commons

Sun, Q. Jena, P., Kim, Y. D., et al. Interactions of Au cluster anions with oxygen. The Journal of Chemical Physics 120, 6510 (2004). Copyright (C) 2004 AIP Publishing LLC.

\section{Downloaded from}

http://scholarscompass.vcu.edu/phys_pubs/170

This Article is brought to you for free and open access by the Dept. of Physics at VCU Scholars Compass. It has been accepted for inclusion in Physics Publications by an authorized administrator of VCU Scholars Compass. For more information, please contact libcompass@vcu.edu. 


\title{
Interactions of Au cluster anions with oxygen
}

\author{
Qiang Sun and Puru Jena \\ Physics Department, Virginia Commonwealth University, Richmond, Virginia 23284-2000 \\ Young Dok Kim, ${ }^{\text {a) }}$ Matthias Fischer, and Gerd Ganteför \\ Department of Physics, University of Konstanz, D-78457 Konstanz, Germany
}

(Received 15 October 2003; accepted 14 January 2004)

\begin{abstract}
Experimental and theoretical evidence is presented for the nondissociative chemisorption of $\mathrm{O}_{2}$ on free $\mathrm{Au}$ cluster anions ( $\mathrm{Au}_{n}{ }^{-}, n=$ number of atoms) with $n=2,4,6$ at room temperature, indicating that the stabilization of the activated di-oxygen species is the key for the unusual catalytic activities of Au-based catalysts. In contrast to $\mathrm{Au}_{n}{ }^{-}$with $n=2,4,6, \mathrm{O}_{2}$ adsorbs atomically on Au monomer anions. For the $\mathrm{Au}$ monomer neutral, calculations based on density functional theory reveal that oxygen should be molecularly bound. On Au dimer and tetramer neutrals, oxygen is molecularly bound with the $\mathrm{O}-\mathrm{O}$ bond being less activated with respect to their anionic counterparts, suggesting that the excess electron in the anionic state plays a crucial role for the $\mathrm{O}-\mathrm{O}$ activation. We demonstrate that interplay between experiments on gas phase clusters and theoretical approach can be a promising strategy to unveil mechanisms of elementary steps in nanocatalysis. (C) 2004 American Institute of Physics. [DOI: 10.1063/1.1666009]
\end{abstract}

\section{INTRODUCTION}

Gold $(\mathrm{Au})$ particles, which are inert in the bulk form, become efficient catalysts for various chemical reactions in the size range below $2-3 \mathrm{~nm}^{1-5}$ This unusual sizedependent catalytic behavior of Au is currently one of the most extensively studied subjects in chemistry, and physics. ${ }^{1-23}$ However, no generally accepted picture for the $\mathrm{O}_{2}$ adsorption on $\mathrm{Au}$ nanoclusters has appeared yet, which is believed to be responsible for the size-selectivity of Aubased catalysis. ${ }^{10}$ In spite of extensive studies in the past, it is still controversial, whether $\mathrm{O}_{2}$ dissociates or not on Aubased catalysts at room temperature. ${ }^{6-11}$

Catalytically active Au particles were suggested to be negatively charged through the charge transfer from defect sites of the oxide supports to $\mathrm{Au}^{6}{ }^{6}$ It was recently shown that the mass-selected $\mathrm{Au}$ cluster anions $\left(\mathrm{Au}_{n}{ }^{-}, n=\right.$ number of gold atoms) in the gas phase exhibit comparable catalytic activities to those of oxide-supported Au particles, confirming the importance of the negative charge on Au clusters for the catalytic activities. ${ }^{6,12-14}$ This result suggests that $\mathrm{Au}_{n}{ }^{-}$ in the gas phase is a good model system to unveil the origin of the size-dependent variations of chemical activities and reaction mechanisms of Au nanocatalysts. ${ }^{12-14}$ It is important to mention that the sizes of the gas phase clusters can be better controlled with respect to those of the metal islands grown on oxide surfaces, even though efforts have recently been made to deposit mass-selected clusters to obtain monodispersed clusters on the surface. ${ }^{6,7}$ Moreover, gas phase cluster data allow direct comparisons with theoretical results. Therefore, size-dependent changes of the chemical activities can be much more precisely followed by studying gas phase clusters.

To shed light on adsorption properties of oxygen on $\mathrm{Au}$

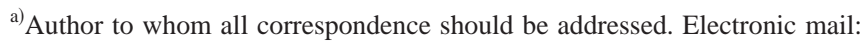
young.kim@uni-konstanz.de
}

cluster anions, we have studied oxygen adsorption on $\mathrm{Au}$ cluster anions consisting of 1,2, 4, and $6 \mathrm{Au}$ atoms using ultraviolet photoelectron spectroscopy (UPS) and density functional theory (DFT) calculations. In particular, $\mathrm{Au}_{2}{ }^{-}$, $\mathrm{Au}_{4}{ }^{-}$, and $\mathrm{Au}_{6}{ }^{-}$have recently been shown to be very active toward CO-oxidation at room temperature, and thus are suitable model systems to study interaction mechanisms of the Au-based catalysts. ${ }^{913}$ We demonstrate that the formation of activated molecular oxygen is an important step for the catalytic reactions of Au nanoparticles.

\section{TECHNICAL DETAILS}

To synthesize $\mathrm{Au}_{n} \mathrm{O}_{2}{ }^{-}$, Au clusters were produced in the Pulsed Arc Cluster Ion Source (PACIS), ${ }^{24}$ and subsequently exposed to $\mathrm{O}_{2}$. In agreement with previous results, evennumbered $\mathrm{Au}$ cluster anions smaller than $\mathrm{Au}_{21}{ }^{-}$generally react with $\mathrm{O}_{2}$, whereas most of the odd-numbered ones are inert in $\mathrm{O}_{2}$ environments. ${ }^{12,13,25}$ There are, however, some exceptions for this even/odd rule of the chemical activities. $\mathrm{Au}_{16}{ }^{-}$is inert toward $\mathrm{O}_{2}$ adsorption, and $\mathrm{Au}_{1}{ }^{-}$and $\mathrm{Au}_{3}{ }^{-}$ partially form $\mathrm{Au}_{n} \mathrm{O}_{2}{ }^{-}(n=1,3)$. The temperature of the clusters is estimated to be room temperature. The mass of clusters was selected using a time-of-flight mass spectrometer, and the UPS spectra of the mass-selected clusters were taken using UV Laser pulse (photon energy $=4.66$ or $6.4 \mathrm{eV}$ ). The energy resolution of our UPS spectra is about $0.1 \mathrm{eV}$.

For theoretical studies, we have used the self-consistent linear combination of atomic orbital-molecular orbital approach. The total energies are calculated using DFT with the generalized gradient approximation for exchangecorrelation potential, which is taken as Perdew-Wang 91 prescription (commonly referred to as PW91). The atomic orbitals are represented by a Gaussian basis. We have used the $6-311++\mathrm{G}(3 d f, 3 p d)$ basis set for oxygen and the Stuttgart relativistic effective core potential basis set for gold. ${ }^{26}$ The structures for the anionic and neutral clusters 
TABLE I. Establishing the accuracy of the basis set and exchange correlation potential by comparing the experimental values of ionization potential (IP), electron affinity (EA), bond length $(d)$, and binding energy (BE).

\begin{tabular}{|c|c|c|c|c|c|c|c|c|}
\hline & \multicolumn{2}{|c|}{ IP $(\mathrm{eV})$} & \multicolumn{2}{|c|}{ EA $(e V)$} & \multicolumn{2}{|c|}{$d(\AA)$} & \multicolumn{2}{|c|}{$\mathrm{BE}(\mathrm{eV})$} \\
\hline & Theor. & Expt. & Theor. & Expt. & Theor. & Expt. & Theor. & Expt. \\
\hline $\mathrm{Au}$ & 9.46 & 9.22 & 2.33 & 2.31 & & & & \\
\hline $\mathrm{O}$ & 14.08 & 13.62 & 1.72 & 1.46 & & & & \\
\hline $\mathrm{O}_{2}$ & 12.33 & 12.07 & 0.44 & 0.45 & 1.22 & 1.21 & & \\
\hline $\mathrm{AuO}$ & & & & & & & 2.47 & $2.30 \pm 0.2$ \\
\hline $\mathrm{Au}_{2}$ & & & 2.06 & 2.02 & 2.56 & 2.47 & 2.12 & 2.31 \\
\hline $\mathrm{Au}_{4}$ & & & 2.82 & 2.77 & & & & \\
\hline
\end{tabular}

were optimized without symmetry constraint using the GAUSSIAN 98 code. $^{27}$ The convergence for energy and force are $0.00001 \mathrm{eV}$ and $0.003 \mathrm{eV} / \AA$, respectively. To check the accuracy of the exchange-correlation potential, we calculated the ionization potential (IP), electron affinity (EA), binding energy $(\mathrm{BE})$ and bond length $(d)$ of $\mathrm{Au}, \mathrm{O}, \mathrm{O}_{2}, \mathrm{AuO}$, $\mathrm{Au}_{2}$, and $\mathrm{Au}_{2}$, and these are compared with the experimental data, as shown in Table I. The good agreement between theory and experiment provides confidence on the accuracy of our numerical procedure.

\section{RESULTS AND DISCUSSIONS}

In the following, we discuss our results on $\mathrm{Au}_{n}{ }^{-}$, $\mathrm{Au}_{n} \mathrm{O}^{-}$, and $\mathrm{Au}_{n} \mathrm{O}_{2}{ }^{-}$. The results are contrasted with calculations of the interaction of $\mathrm{O}_{2}$ with the neutral $\mathrm{Au}$ clusters.

\section{A. Bare Au cluster anions}

In Fig. 1, the calculated structures of pure Au cluster anions consisting of $1-4 \mathrm{Au}$ atoms are presented. The $\mathrm{Au}-\mathrm{Au}$ bond lengths are generally about 2.6-2.7 $\AA$, which are significantly shorter than the bulk value. $\mathrm{Au}_{3}{ }^{-}$shows a slightly bent structure, and the $\mathrm{Au}_{4}{ }^{-}$exhibits a triangle frame with the fourth $\mathrm{Au}$ atom attached to the apex of the triangle. These results are in line with previous studies. ${ }^{28,29}$

For $\mathrm{Au}^{-}$, the calculated detachment energy from the singlet state of the anion to the doublet of the neutral amounts to $2.33 \mathrm{eV}$, which is in agreement with the experimentally determined vertical detachment energy $(2.31 \mathrm{eV})$. For $\mathrm{Au}_{2}{ }^{-}$, the experimentally found peaks at 2.1 and $4 \mathrm{eV}$ can be assigned to the vertical detachments from the doublet state of the anion to the singlet and triplet state of the neutral, respectively. For $\mathrm{Au}_{3}{ }^{-}$, the experimentally determined vertical detachment energy corresponds to the calculated transition energy from the singlet state of the anion to the doublet of the neutral. For $\mathrm{Au}_{4}{ }^{-}$, the peaks at 2.8 and $4.2 \mathrm{eV}$ in the UPS spectrum are consistent with the theoretically determined energies arising from the transitions from the doublet to singlet and doublet to triplet transitions, respectively. The good agreement between theory and experiment demonstrates a high reliability of the computational method in the present work.

\section{B. Chemisorption of atomic oxygen on Au cluster anions $\left(\mathrm{Au}_{n} \mathrm{O}^{-}\right)$}

To shed light on the electronic and geometric structures of the Au cluster anions reacted with a single oxygen atom, UPS studies and DFT calculations were carried out, as shown in Fig. 2. In our cluster source, the partial pressure of atomic oxygen generated by the dissociation of molecular oxygen in the arc is eventually quite high, leading to the formation of gold monoxide clusters. ${ }^{24,29}$

Analogous to the case of the pure Au cluster anions, peak positions in the UPS spectra of $\mathrm{Au}_{n} \mathrm{O}^{-}$are in agreement with the calculated transition energies (Fig. 2), demonstrating that our calculation method is suitable for dealing with the interactions between oxygen and Au clusters. It is interesting to note that upon the chemisorption of atomic oxygen, the geometric structure of $\mathrm{Au}_{4}{ }^{-}$is significantly modified. The $\mathrm{Au}-\mathrm{Au}$ bond length located nearest to the oxygen atom is changed from 2.76 to $2.63 \AA$ upon oxygen adsorption. Contraction of the metal-metal bonding upon oxygen adsorption has also been found on transition metal surfaces, which can be roughly explained by the transfer of electrons from antibonding bands of metals to oxygen, leading to the enhanced metal-metal bonding. ${ }^{30}$ In addition to the change in bond length, the triangle structure becomes slightly distorted upon oxygen adsorption.

\section{Chemisorption of $\mathrm{O}_{2}$ on Au cluster anions $\left(\mathrm{Au}_{n} \mathrm{O}_{2}{ }^{-}\right)$}

In Fig. 3, the UPS spectra of $\mathrm{Au}_{n} \mathrm{O}_{2}{ }^{-}$(produced in $\mathrm{O}_{2}$ atmosphere) with $n=1,2,4,6$ taken using a laser with a photon energy of $4.66 \mathrm{eV}$ are compared. UPS spectra for
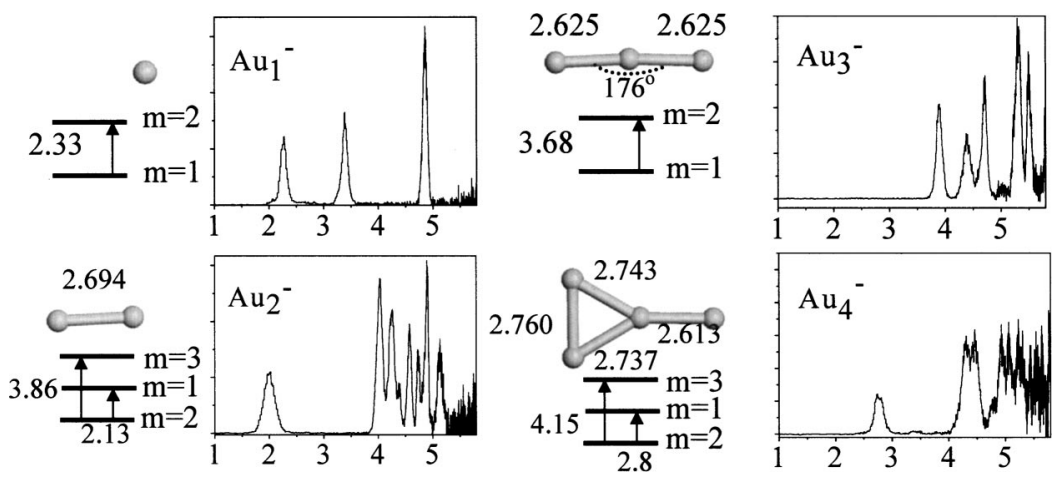

FIG. 1. Calculated transition energies from the anionic to the neutral state for the $\mathrm{Au}_{n}{ }^{-}$with $n=1-4$, and their equilibrium structures. Experimentally taken UPS spectra (photon energy $=6.4 \mathrm{eV}$ ) are displayed for comparison. 


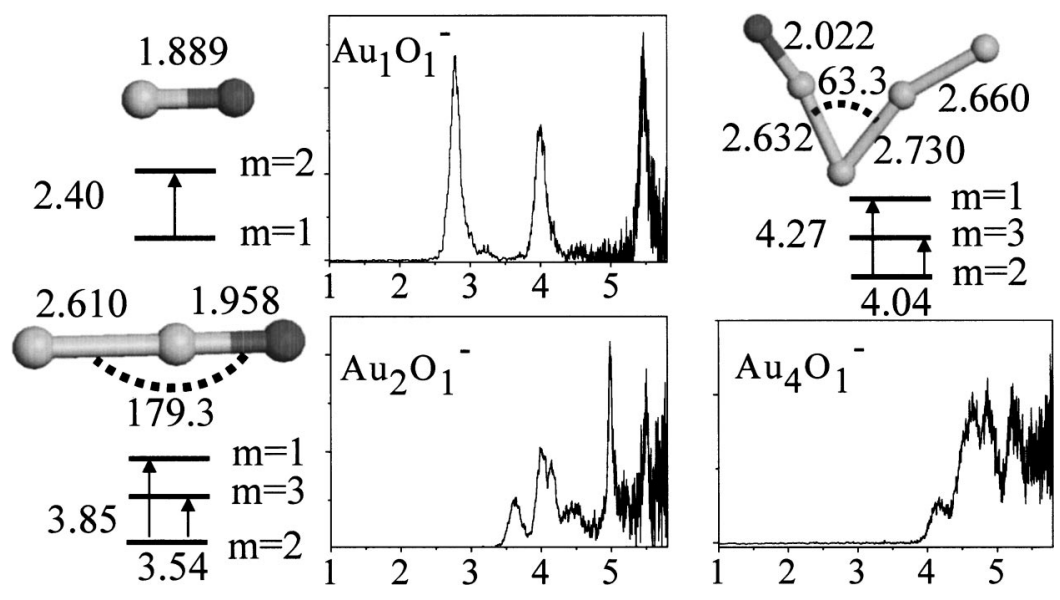

FIG. 2. Calculated transition energies from the anionic to the neutral state for the $\mathrm{AuO}_{n}{ }^{-}$with $n=1-4$, and their equilibrium structures. Experimentally taken UPS spectra (photon energy $=6.4 \mathrm{eV}$ ) are displayed for the comparison.

$\mathrm{Au}_{n} \mathrm{O}_{2}{ }^{-}$with $n=2,4,6$, exhibit vibrational fine structures of about 150-180 meV corresponding to the O-O stretching frequencies, indicative of the nondissociative adsorption of $\mathrm{O}_{2}$. The vibrational frequencies in Fig. 3 are much higher than those found for the di-oxygen species on transition metal surfaces. ${ }^{31}$ However, note that the vibrational frequencies in the UPS spectra correspond to those of the neutral clusters having geometries of their respective anions. In the anionic states, the additional electrons occupy the antibinding $2 \pi^{*}$ orbitals of $\mathrm{O}_{2}$, further activating the $\mathrm{O}-\mathrm{O}$ bonding, and decreasing the $\mathrm{O}-\mathrm{O}$ stretching frequencies. ${ }^{14}$ The fact that we can observe the strong vibrational structures of $\mathrm{O}-\mathrm{O}$ indicates that the $\mathrm{O}-\mathrm{O}$ bond length should be significantly altered upon the one electron detachment. The additional electron in the anionic state is strongly localized on oxygen, in line with recent theoretical studies, which found strong resonances of the $\mathrm{O}_{2}-2 \pi^{*}$ and the highest occupied molecular orbitals (HOMOs) of the Au cluster anions. ${ }^{32}$

To obtain a better understanding on chemisorption mechanism of $\mathrm{O}_{2}$ on catalytically active Au clusters, UPS spectra of $\mathrm{Au}_{n} \mathrm{O}_{2}{ }^{-}$with $n=2,4$ are collected using a laser

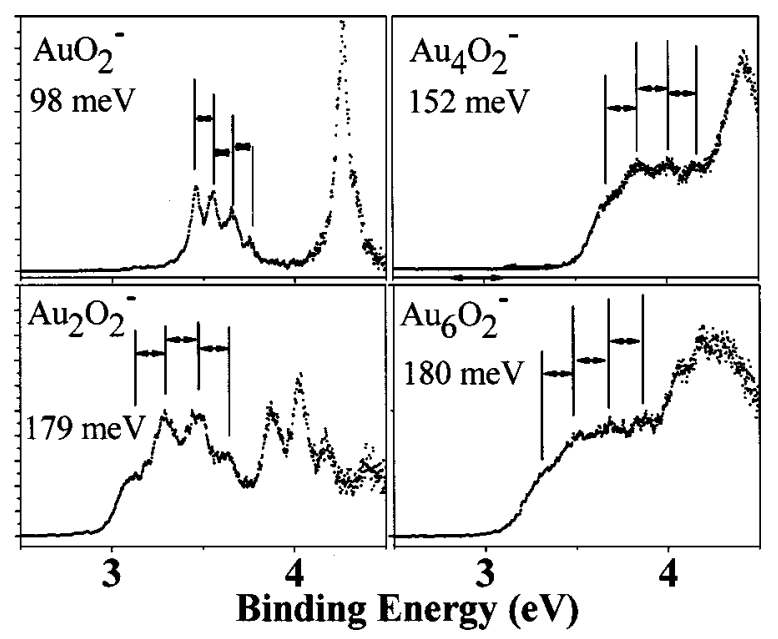

FIG. 3. UPS spectra of $\mathrm{A}_{n} \mathrm{O}_{2}{ }^{-}$for $n=1,2,4,6$ using a laser with a photon energy of $4.66 \mathrm{eV}$. For $n=2,4,6$, vibrational fine structures are resolved, which correspond to the stretching frequencies of dioxygen species. with a higher photon energy $(6.4 \mathrm{eV})$, as indicated in Fig. 4. The distinct features of the pure Au cluster anions existing at the binding energies below about $4.7 \mathrm{eV}$ completely disappear upon $\mathrm{O}_{2}$ adsorption, and broad features between 3 and $4.5 \mathrm{eV}$ (marked with A in Fig. 4) appear, followed by several narrower peaks. Comparing the UPS spectra of the $\mathrm{Au}_{n} \mathrm{O}_{2}{ }^{-}$ with those of the respective pure Au cluster anions, the valence band structures of $\mathrm{Au}_{n}{ }^{-}$are completely changed upon $\mathrm{O}_{2}$ adsorption, indicating significantly large interactions between $\mathrm{O}_{2}$ and these $\mathrm{Au}$ cluster anions. It should be noted that not only HOMOs but also other occupied MOs of the $\mathrm{Au}$ cluster anions with higher binding energies participate in the $\mathrm{O}_{2}$ chemisorption (Fig. 4). As a result of the charge transfer from the HOMOs of the Au cluster anions to oxygen, $\mathrm{O}_{2}$ can approach closer to Au atoms, which then allows contribution of other localized MOs of the Au cluster anions with higher binding energies to the $\mathrm{O}_{2}$ chemisorption. Due to this strong interaction between $\mathrm{Au}$ and oxygen, $\mathrm{O}_{2}$ can be highly activated, leading to enhanced chemical activities toward vari-
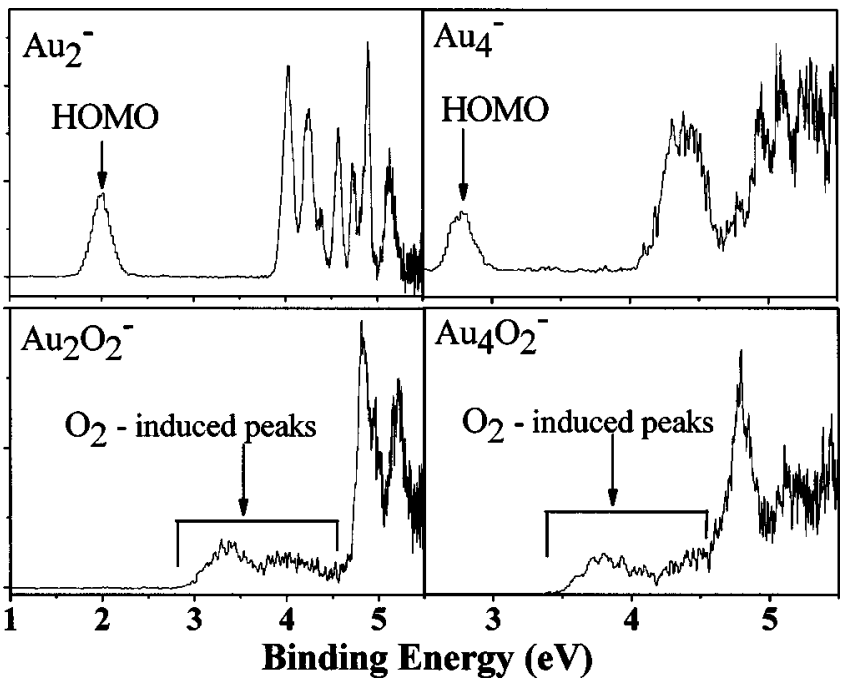

FIG. 4. Comparison of the UPS spectra for $\mathrm{Au}_{n}{ }^{-}$and $\mathrm{A}_{n} \mathrm{O}_{2}{ }^{-}$with $n=2,4$ $($ photon energy $=6.4 \mathrm{eV})$. 


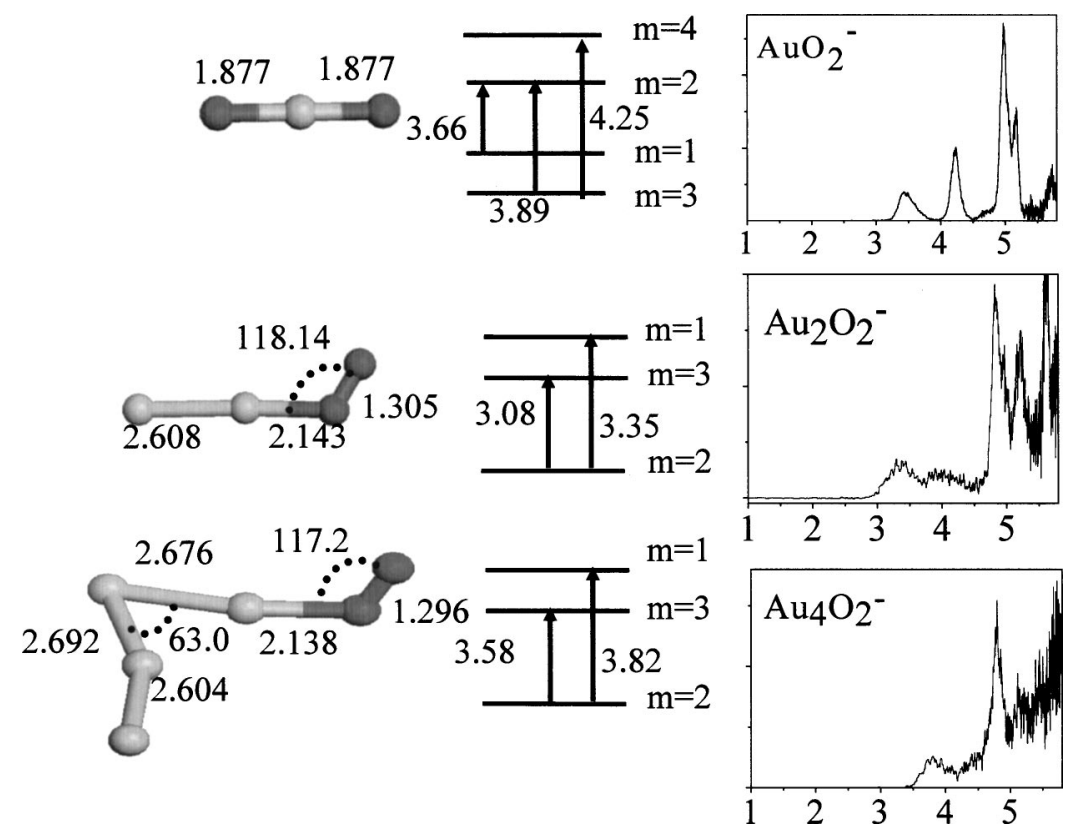

FIG. 5. Equilibrium structures of $\mathrm{Au}_{n} \mathrm{O}_{2}{ }^{-}$with $n=1,2,4$ obtained from DFT calculations. Transition energies from the anionic to the neutral states are also shown. For comparison, experimentally taken UPS spectra (photon energy $=6.4 \mathrm{eV}$ ) are displayed.

ous chemical reactions such as $\mathrm{CO}$-oxidation, in which activation of the $\mathrm{O}-\mathrm{O}$ bonding is essential.

To better understand the structure of adsorbed oxygen on these Au cluster anions, first principle calculations were carried out. First, we focus on the even-numbered Au cluster anions. Theoretical results show that di-oxygen species are attached to Au cluster anions with one oxygen atom, and the $\mathrm{O}-\mathrm{O}$ bond lengths amount to about $1.30 \AA$, which are significantly larger than that of an $\mathrm{O}_{2}$ molecule $(1.21 \AA)$ (Fig. $5)$. To establish the accuracy of these calculated structures, we compare the calculated vertical detachment energies with the peaks in the photodetachment spectra in Fig. 5. For $\mathrm{AuO}_{2}{ }^{-}$, there are two spin multiplet structures (singlet and triplet) that are $0.23 \mathrm{eV}$ apart in energy. The resulting transitions from the anion with spin multiplicity $M$ to the neutral with spin multiplicities, $M \pm 1$, are identified in Fig. 5. Note that the calculated transition energies again compare very well with the measured peaks, demonstrating a high reliability of the theoretical calculations. Electron affinities and vertical detachment energies of the $\mathrm{Au}_{n} \mathrm{O}_{2}{ }^{-}$from theory agree with the experimentally found values within $0.2 \mathrm{eV}$ (Table II). The $\mathrm{O}-\mathrm{O}$ stretching frequencies in the DFT calculations are 142 and $145 \mathrm{meV}$ for the $\mathrm{Au}_{2} \mathrm{O}_{2}$ and $\mathrm{Au}_{4} \mathrm{O}_{2}$ clusters which are close to the experimental values $(150-180 \mathrm{meV})$.

TABLE II. Comparison of experimental and theoretical electron affinities (EA), vertical detachment energies (VDE), and vibrational frequencies $(f)$ for $\mathrm{AuO}_{2}{ }^{-}, \mathrm{Au}_{2} \mathrm{O}_{2}^{-}$, and $\mathrm{Au}_{4} \mathrm{O}_{2}^{-}$.

\begin{tabular}{lcccccrrr}
\hline \hline & \multicolumn{2}{c}{ EA $(\mathrm{eV})$} & & \multicolumn{2}{c}{ VDE $(\mathrm{eV})$} & & \multicolumn{2}{c}{$f(\mathrm{meV})$} \\
\cline { 2 - 3 } & Theor. & Expt. & & Theor. & Expt. & & Theor. & Expt. \\
\hline $\mathrm{AuO}_{2}$ & 2.95 & 3.30 & & 3.66 & 3.46 & & 87 & $88-108$ \\
$\mathrm{Au}_{2} \mathrm{O}_{2}$ & 2.96 & 2.94 & & 3.35 & 3.11 & & 142 & $169-189$ \\
$\mathrm{Au}_{4} \mathrm{O}_{2}$ & 3.44 & 3.50 & & 3.82 & 3.70 & & 145 & $142-162$ \\
\hline \hline
\end{tabular}

For Au monomer anions, the vibrational frequency is much lower than those for the other clusters (Fig. 3). The 98 $\mathrm{meV}$ can be tentatively assigned to the $\mathrm{Au}-\mathrm{O}$ stretching frequency, indicating that $\mathrm{O}_{2}$ dissociatively adsorbs on $\mathrm{Au}$ monomer anions. In the DFT calculations for Au monomer anions, dissociative adsorption of oxygen on $\mathrm{Au}^{-}$forming a linear $\mathrm{O}-\mathrm{Au}-\mathrm{O}^{-}$structure is energetically more favorable than the molecular adsorption by about $0.7 \mathrm{eV}$, in agreement with our assignments of the vibrational fine structures in the UPS spectrum (Figs. 3, 5, and 6). Again, the electron affinity, the vertical detachment energy, and the vibrational frequency of $\mathrm{AuO}_{2}{ }^{-}$from the theoretical calculations are consistent with experimental data (Table II).

To study the dissociation process of $\mathrm{O}_{2}$ as it approaches an $\mathrm{Au}$ monomer anion in detail, we have calculated the total energies of $\mathrm{AuO}_{2}{ }^{-}$as a function of the $\mathrm{O}-\mathrm{Au}-\mathrm{O}$ bond angle. The results are plotted in Fig. 6. Note that the two energy minima corresponding to molecular versus dissociative adsorption are separated by a large energy barrier of about $2 \mathrm{eV}$. In the neutral case, the energy barrier that separates the two minima is also of the same order. The only difference is that the $\mathrm{O}_{2}$ binds dissociatively to $\mathrm{Au}^{-}$and molecularly to the neutral $\mathrm{Au}$ atom. The large energy barriers suggest that the dissociative adsorption of $\mathrm{O}_{2}$ on $\mathrm{Au}^{-}$can only be observed under some suitable experimental conditions, for example in the presence of large amounts of atomic oxygen in the reagent atmosphere.

Our results suggest that activated molecular oxygen is an important intermediate in Au-based catalysts. On Ptgroup metal surfaces, $\mathrm{CO}$ oxidation usually takes place through the Langmuir-Hinshelwood mechanism, in which $\mathrm{O}_{2}$ first dissociates and then reacts with $\mathrm{CO}$ to form $\mathrm{CO}_{2} \cdot{ }^{33}$ On Au cluster anions, in contrast, the stabilization of the activated molecular oxygen at room temperature can open new reaction channels (e.g., $\mathrm{CO}$ oxidation mediated by 

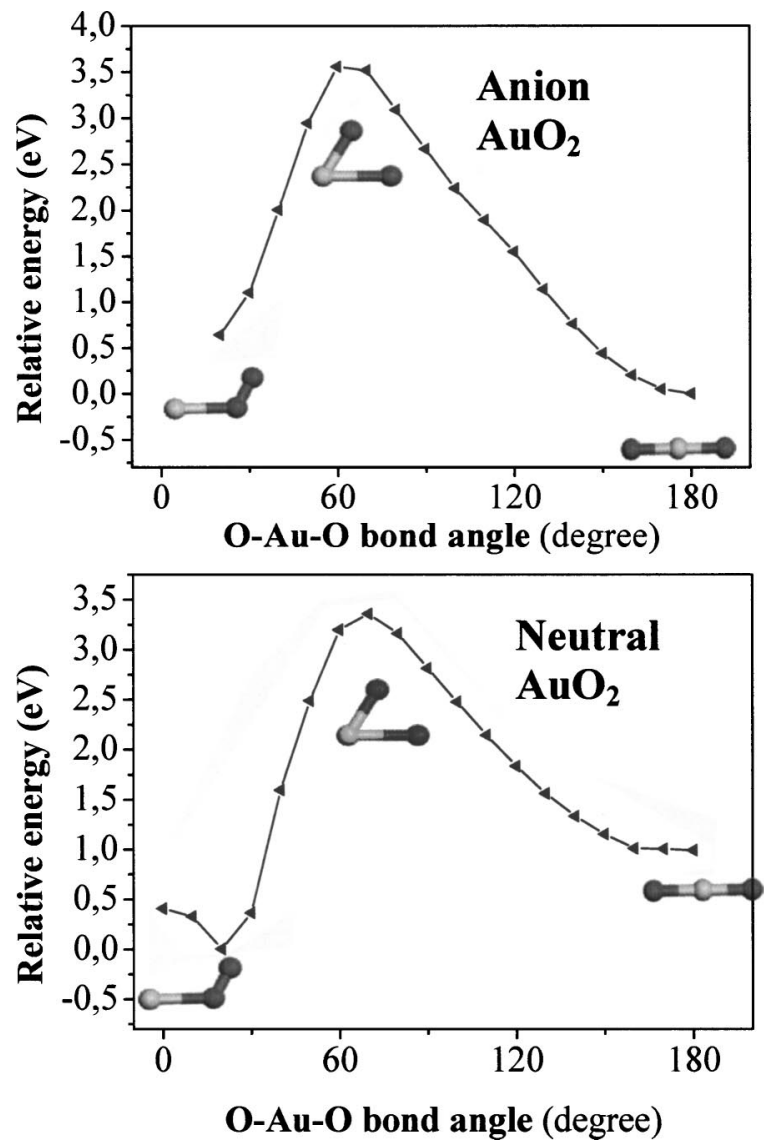

FIG. 6. Energy diagram for the dissociation of oxygen molecule on anionic and neutral Au monomer calculated based on DFT calculations.

carbonate-like species), ${ }^{2}$ responsible for the low temperature $\mathrm{CO}$ oxidation. Molecular adsorption of oxygen can play a vital role for the enhanced activities of gold clusters toward many other catalytic reactions such as partial oxidation of propylene, in which formation of hydroperoxide $\left(\mathrm{H}_{2} \mathrm{O}_{2}\right)$ is suggested to be important. ${ }^{15}$ Note that for the formation of the hydroperoxide, nondissociative adsorption of oxygen is essential.

\section{D. $\mathrm{O}_{2}$ adsorption on Au neutral clusters}

DFT calculations are carried out for the $\mathrm{O}_{2}$ adsorption on neutral Au clusters to study the role of the additional charge in the anionic state for the $\mathrm{O}_{2}$ chemisorption. As mentioned before, for $\mathrm{Au}$ monomer, molecular adsorption is more stable than the dissociative adsorption of $\mathrm{O}_{2}$, which is different from the result of $\mathrm{Au}$ monomer anions (Fig. 6). An additional charge on Au plays a crucial role for the dissociation of $\mathrm{O}_{2}$. It is interesting to note that it is not only the activation barrier for the dissociative adsorption on $\mathrm{Au}$ monomers, which is influenced by the existence of the additional charge, but the metastable and ground state in the chemisorption can be exchanged depending on the charge state in the Au monomer.

The calculated structures of $\mathrm{O}_{2}$ adsorbed on $\mathrm{Au}$ dimers and tetramers show that the $\mathrm{O}-\mathrm{O}$ bond lengths in the neutral states are shorter with respect to the $\mathrm{O}-\mathrm{O}$ bond lengths in their anionic counterparts by about $0.05 \AA$ (Fig. 7). Obvi-
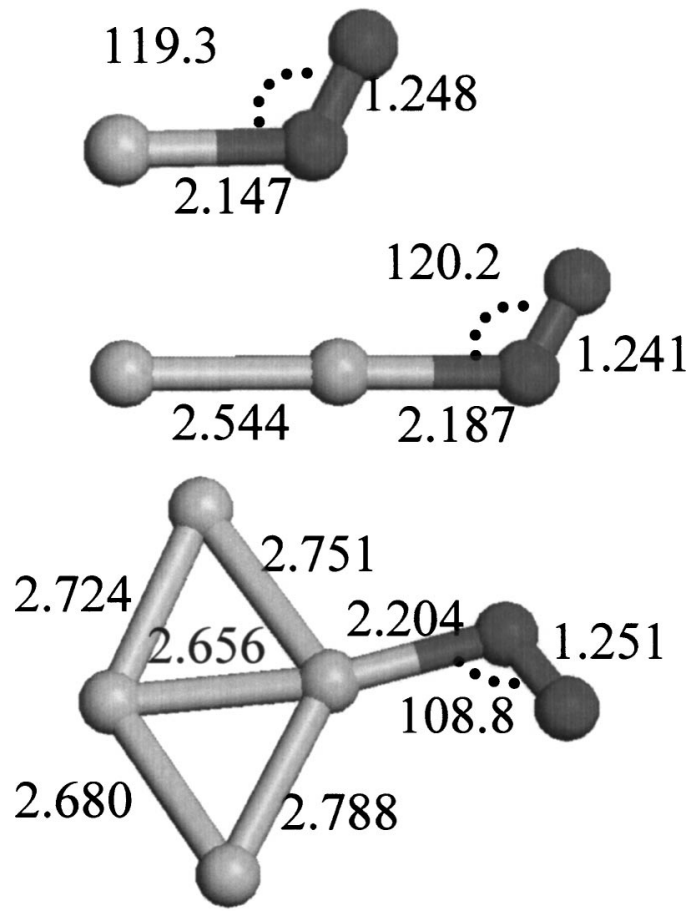

FIG. 7. Equilibrium geometries of molecularly bound oxygen on neutral $\mathrm{Au}$ clusters from DFT calculations are displayed.

ously, the additional electron in the anionic state is important for the activation of the $\mathrm{O}-\mathrm{O}$ bonding.

\section{E. Interaction mechanism}

We now examine electronic structures of neutral and anionic $\mathrm{Au}_{n} \mathrm{O}_{2}$ clusters to answer two fundamental questions in nano-gold catalysis: what role does the extra electron play and what role does the reduced size play? Note that the electronic ground state of $\mathrm{O}_{2}$ is in the triplet state, having two unpaired electrons in the degenerate $2 \pi^{*}$ antibonding orbitals. It can be expected that charge transfers from metal systems to these orbitals would occur when $\mathrm{O}_{2}$ is adsorbed, which is favorable for electron pairing and adsorption. However, it should be noted that $\mathrm{Au}$ is the most electronegative metal, comparable to selenium, and only slightly more electropositive than sulfur (S) and iodine (I). Its electron affinity is actually greater than that of $\mathrm{O}$, and therefore it can form compounds such as $\mathrm{Au}^{-} \mathrm{Cs}^{+}$where gold becomes anionic. ${ }^{34}$ Due to the high electronegativity of $\mathrm{Au}$, charge transfers take place from oxygen to $\mathrm{Au}$, when an $\mathrm{O}_{2}$ molecule interacts with even-numbered neutral $\mathrm{Au}$ clusters, forming partially negatively charged $\mathrm{Au}$. In $\mathrm{Au}_{2} \mathrm{O}_{2}$ and $\mathrm{Au}_{4} \mathrm{O}_{2}$, Mulliken population analysis indicates that there are 0.08 and 0.04 electrons transferred from $\mathrm{O}_{2}$ to $\mathrm{Au}_{2}$ and $\mathrm{Au}_{4}$, respectively. The minor charge transfer results in very weak interactions giving small energy gains of 0.45 and $0.41 \mathrm{eV}$ for $\mathrm{Au}_{2}$ and $\mathrm{Au}_{4}$, respectively (see Table III).

In contrast to the case of neutral clusters, anionic clusters can better facilitate electron donation to adsorbates, resulting in stronger interactions between $\mathrm{Au}$ and oxygen through large charge transfers. For $\mathrm{Au}_{2} \mathrm{O}_{2}{ }^{-}, 0.36$ electrons are transferred to $\mathrm{O}_{2}$, and the $\mathrm{Au}-\mathrm{O}_{2}$ interaction energy and the $\mathrm{O}-\mathrm{O}$ bond length increase to $1.25 \mathrm{eV}$ and $1.31 \AA$, respectively. For 
TABLE III. Comparison of electronic and structural parameters for anion and neutral clusters. $\Delta q$ is the charge transfer from Au cluster to $\mathrm{O}_{2}$ molecule. $\Delta E$ is the energy gain when $\mathrm{O} 2$ interacts with $\mathrm{Au}$ cluster. $R 1$ is the bond length between the two $\mathrm{O}$ atoms, $R 2$ is the nearest distance between $\mathrm{Au}$ and $\mathrm{O}$.

\begin{tabular}{lrrrrrrrr}
\hline \hline & \multicolumn{2}{c}{$\mathrm{AuO}_{2}$} & & \multicolumn{2}{c}{$\mathrm{Au}_{2} \mathrm{O}_{2}$} & & & \multicolumn{2}{c}{$\mathrm{Au}_{4} \mathrm{O}_{2}$} \\
\cline { 2 - 3 } & Anion & Neutral & & Anion & Neutral & & Anion & Neutral \\
\hline$\Delta q(e)$ & +1.22 & +0.04 & & +0.36 & -0.08 & & +0.27 & -0.04 \\
$\Delta E(\mathrm{eV})$ & -1.04 & -0.43 & & -1.25 & -0.45 & & -1.07 & -0.41 \\
$R 1(\AA)$ & 3.75 & 1.25 & & 1.31 & 1.24 & & 1.30 & 1.25 \\
$R 2(\AA)$ & 1.88 & 2.15 & & 2.14 & 2.19 & & 2.14 & 2.20 \\
\hline \hline
\end{tabular}

$\mathrm{Au}_{4} \mathrm{O}_{2}{ }^{-}, \mathrm{Au}_{4}{ }^{-}$transfers 0.27 electrons to $\mathrm{O}_{2}$ with an adsorption energy of $1.07 \mathrm{eV}$. The $\mathrm{O}_{2}-\mathrm{Au}$ binding energies calculated in the present work agree better with experimentally determined values in comparison to the previous theoretical calculations. ${ }^{35}$ Table III gives a comparison of the structural and electronic parameters of anion and neutral clusters, showing that the more charge $\mathrm{O}_{2}$ gets, the longer the $\mathrm{O}-\mathrm{O}$ bond length becomes, the shorter the $\mathrm{Au}-\mathrm{O}$ distance becomes, and the larger the adsorption energy becomes. In $\mathrm{AuO}_{2}{ }^{-}$, there are 1.22 electrons transferred from $\mathrm{Au}^{-}$. This significant charge transfer activates the $\mathrm{O}-\mathrm{O}$ bond greatly, and dissociates $\mathrm{O}_{2}$.

Combining UPS experiments and DFT calculations, we found that even at the smallest size, the even-numbered neutral Au cluster interacts very weakly with $\mathrm{O}_{2}$. Thus, for the even-numbered $\mathrm{Au}$ cluster anions, quantum size effects do not appear to be a dominant mechanism for the reactivity. However, when an additional charge is introduced to $\mathrm{Au}$ clusters, the reactivity with $\mathrm{O}_{2}$ is increased significantly. In $\mathrm{Au}$ monomer anions, dissociative chemisorption of $\mathrm{O}_{2}$ takes place, indicative of a very strong $\mathrm{Au}-\mathrm{O}$ interaction. Due to the large electronegativity of gold atom, Au clusters easily attract electrons from support materials to become negatively charged. This electron transfer to the Au catalysts enhances interactions with $\mathrm{O}_{2}$, as does the catalytic activity. Therefore the substrate effects (charge transfer from substrate to $\mathrm{Au}$ clusters) can be important to understand the $\mathrm{Au}$ nanocatalysis. ${ }^{6}$

\section{CONCLUSION}

A synergistic study involving UPS experiments and DFT calculations revealed that high chemical activities of evennumbered $\mathrm{Au}$ nanoclusters result from the stabilization of molecular oxygen on negatively charged Au clusters. For the anionic Au monomer, in contrast, dissociative adsorption of oxygen was found. For the neutral clusters, $\mathrm{O}_{2}$ is less activated with respect to the anionic clusters. These results indicate that the additional electrons in the anionic states of these
Au clusters are crucial for the activation of the $\mathrm{O}-\mathrm{O}$ bonding. We demonstrate that interplay between cluster physics in combination with theoretical approach is a promising strategy to unveil mechanisms of elementary steps on various nanocatalysts.

\section{ACKNOWLEDGMENTS}

We acknowledge the financial support from DFG (Deutsche Forschungsgemeinschaft). P.J. and Q.S. would like to acknowledge partial support from Philip Morris, USA.

${ }^{1}$ M. Valden, X. Lai, and D. W. Goodman, Science 281, 1647 (1998).

${ }^{2}$ M. Haruta, S. Tsubota, T. Kobayashi, H. Kageyama, M. J. Genet, and B. Delmon, J. Catal. 144, 175 (1993).

${ }^{3}$ M. Okumura, J. M. Coronado, J. Soria, M. Haruta, and J. C. Conesa, J. Catal. 203, 168 (2001).

${ }^{4}$ H. Liu, A. I. Kozlov, A. P. Kozlova, T. Shido, K. Asakura, and Y. Iwasawa, J. Catal. 185, 252 (1999).

${ }^{5}$ T. S. Kim, J. D. Stiehl, C. T. Reeves, R. J. Meyer, and C. B. Mullins, J. Am. Chem. Soc. 125, 2018 (2003).

${ }^{6}$ A. Sanchez, S. Abbet, U. Heiz, W. D. Schneider, H. Häkkinen, R. N. Barnett, and U. Landman, J. Phys. Chem. A 103, 9573 (1999).

${ }^{7}$ H. Häkkinen, S. Abbet, A. Sanchez, U. Heiz, and U. Landman, Angew. Chem. Int. Ed. 42, 1297 (2003).

${ }^{8}$ Z.-P. Liu, P. Hu, and A. Alavi, J. Am. Chem. Soc. 124, 14770 (2002).

${ }^{9}$ H. Häkkinen and U. Landman, J. Am. Chem. Soc. 123, 9704 (2001).

${ }^{10}$ G. Mills, M. S. Gordon, and H. Metiu, Chem. Phys. Lett. 359, 493 (2002).

${ }^{11}$ N. Lopez and J. K. Norskov, J. Am. Chem. Soc. 124, 11262 (2002).

${ }^{12}$ B. E. Salisbury, W. T. Wallace, and R. L. Whetten, Chem. Phys. 262, 131 (2000).

${ }^{13}$ W. T. Wallace and R. L. Whetten, J. Am. Chem. Soc. 124, 7499 (2002).

${ }^{14}$ D. Stolcic, M. Fischer, G. Ganteför, Y. D. Kim, Q. Sun, and P. Jena, J. Am. Chem. Soc. 125, 2848 (2003).

${ }^{15}$ T. Hayashi, K. Tanaka, and M. Haruta, J. Catal. 178, 566 (1998).

${ }^{16}$ H.-G. Boyen, G. Kästle, F. Weigl et al., Science 297, 1533 (2002).

${ }^{17}$ F. Boccuzzi and A. Chiorino, J. Phys. Chem. B 104, 5414 (2002).

${ }^{18}$ V. A. Bondzie, S. C. Parker, and C. T. Campbell, J. Vac. Sci. Technol. A 17, 1717 (1999).

${ }^{19}$ J.-D. Grundwaldt, M. Maciejewski, O. S. Becker, P. Fabrizioli, and A. Baiker, J. Catal. 186, 458 (1999).

${ }^{20}$ C. T. Campbell, S. C. Parker, and D. E. Starr, Science 298, 811 (2002).

${ }^{21}$ A. Cho, Science 299, 1684 (2003).

${ }^{22}$ L. D. Socaciu, J. Hagen, T. M. Bernhardt, L. Wöste, U. Heiz, H. Hakkinen, and U. Landman, J. Am. Chem. Soc. 125, 10437 (2003).

${ }^{23}$ W. T. Wallace, R. B. Wyrwas, R. L. Whetten, R. Mitric, and V. BonacicKoutecky, J. Am. Chem. Soc. 125, 8408 (2003).

${ }^{24}$ S. Burkart, N. Blessing, B. Klipp, J. Müller, G. Ganteför, and G. Seifert, Chem. Phys. Lett. 301, 546 (1999).

${ }^{25}$ T. H. Lee and K. M. Ervin, J. Phys. Chem. 98, 10023 (1994).

${ }^{26}$ M. Dolg, H. Stoll, H. Preuss, and R. M. Pitzer, J. Phys. Chem. 97, 5852 (1993).

${ }^{27}$ M. J. Frisch et al., GAUSSIAN 98, Gaussian, Pittsburgh, PA (1998).

${ }^{28}$ H. Häkkinen and U. Landman, Phys. Rev. B 62, R2287 (2000).

${ }^{29}$ D. Fischer, W. Andreoni, A. Curioni, H. Grönbeck, S. Burkart, and G. Ganteför, Chem. Phys. Lett. 361, 389 (2000).

${ }^{30}$ H. Over, Prog. Surf. Sci. 58, 249 (1998).

${ }^{31}$ H. Steininger, S. Lehwald, and H. Ibach, Surf. Sci. 123, 1 (1982).

${ }^{32}$ B. Yoon, H. Häkkinen, and U. Landman, J. Phys. Chem. A 107, 4066 (2003).

${ }^{33}$ T. Engel and G. Ertl, Adv. Catal. 28, 1 (1979).

${ }^{34}$ G. C. Bond, Catal. Today 72, 5 (2002).

${ }^{35}$ W. T. Wallace, A. J. Leavitt, and R. L. Whetten, Chem. Phys. Lett. 368, 774 (2003). 